\title{
Labor Promotes Neonatal Neutrophil Survival and Lipopolysaccharide Responsiveness
}

\author{
ELEANOR J. MOLLOY, AMANDA J. O’NEILL, JULIE J. GRANTHAM, \\ MARGARET SHERIDAN-PEREIRA, JOHN M. FITZPATRICK, DAVID W. WEBB, AND \\ R. WILLIAM G. WATSON
}

\begin{abstract}
Department of Surgery [E.J.M., A.J.O., J.M.F., R.W.G.W.], Mater Misericordiae University Hospital, Conway Institute of Biomolecular and Biomedical Research; Department of Paediatrics [E.J.M., J.J.G., M.S.-P.], Coombe Women's Hospital; and Department of Neurology [D.W.W.], Our Lady's Hospital for Sick Children, University College, Dublin, Ireland
\end{abstract}

\begin{abstract}
ABSTR
Labor is a mild proinflammatory state that is associated with
fetal leukocytosis. Elective cesarean section has been linked with
increased neonatal morbidity, which may be partially immune
mediated. We hypothesized that labor may alter neutrophil phe-
notype and thereby decrease neonatal complications. We char-
acterized neutrophil function and survival in normal neonates
after either uncomplicated vaginal delivery (VD) or elective
cesarean section (CS) without labor. Spontaneous neutrophil
apoptosis is delayed in cord blood neutrophils of neonates after
normal labor (VD) compared with CS, as assessed by propidium
iodide DNA incorporation using flow cytometry. This demon-
strates their ability to maintain an inflammatory response. CD11b
expression on neonatal neutrophils after CS is decreased, pro-
viding further evidence of altered activation or priming. Lipo-
polysaccharide responsiveness, characterized by CD11b and ap-
\end{abstract}
Elective cesarean section (CS) is generally perceived as a low-risk procedure with minimal maternal or neonatal morbidity and mortality. However, it is not risk-free and carries significantly increased neonatal morbidity. Respiratory complications are highest in infants who are delivered by CS without labor (1-3). The neutrophil has been implicated in the pathogenesis of both adult and neonatal respiratory distress syndromes (4-7). Delayed pulmonary neutrophil apoptosis in respiratory distress syndrome (8) and adult respiratory distress syndrome (9) contributes to the pulmonary neutrophilia. Furthermore, decreased neutrophil apoptosis in the tracheal fluid of preterm infants is associated with the development of chronic lung disease (10). The pathogenesis of other inflam-

Received June 24, 2003; accepted November 27, 2003.

Correspondence: R. William G. Watson, Ph.D., Department of Surgery, University College Dublin, Mater Misericordiae University Hospital, 47 Eccles Street, Dublin 7, Ireland; e-mail: bwatson@mater.ie

Supported by grants from the Health Research Board of Ireland (Clinical Research Fellowship to E.J.M.); the Mater College, Ireland; and the Children' Research Fund, Our Lady's Hospital for Sick Children, Ireland.

DOI: 10.1203/01.PDR.0000130473.30874.B6 optosis, is similar in VD and adults, but CS-derived neutrophils are unresponsive. Baseline TLR-4 levels are elevated in CS in contrast to the other groups, although expression is not upregulated by lipopolysaccharide co-incubation. Neonatal neutrophil survival and function are altered by labor and may increase antibacterial function and neutrophilia. This suggests that labor of any duration may be immunologically beneficial to the normal term neonate. (Pediatr Res 56: 99-103, 2004)
CS, cesarean section
LPS, lipopolysaccharide
TLR-4, toll-like receptor-4
VD, vaginal delivery

matory conditions such as pancreatitis, inflammatory bowel disease, and the systemic inflammatory response syndrome are also associated with delayed neutrophil apoptosis (10-12).

Labor is associated with a fetal leukocytosis and elevation of the neonate's systemic neutrophil count $(13,14)$ compared with cesarean section. Neonatal neutrophils after CS are known to have delayed apoptosis compared with adult control subjects (15), and this may contribute to their physiologic neutrophilia $(16,17)$. We hypothesized that mode of delivery affected neonatal neutrophil survival and function. We therefore compared neutrophil phenotype in infants who were born by normal vaginal delivery (VD) with those who were born by elective CS without labor.

\section{METHODS}

Reagents and antibodies. Dulbecco's modified Eagle's medium, penicillin, streptomycin solution, L-glutamine, and FCS were purchased from GIBCO Life Technologies (Paisley, UK). Dextran T-500 and Ficoll were purchased from Pharmacia (Buckinghamshire, UK). E-lyse was purchased from Cardinal 
Associates (Santa Fe, NM, U.S.A.). CD11b (LeuTM-15), PE, and CD33:PE were obtained from Becton Dickinson (San Jose, CA, U.S.A.). Monoclonal anti-h-FAS (CH-11) fluorescein was bought from R\&D systems (Minneapolis, MN, U.S.A.). Anti-human TLR4 MAb was purchased from Medical and Biologic Laboratories (Nagoya, Japan). Anti-mouse IgG conjugated with PE was obtained from Immunotech (Ontario, Canada). All remaining chemicals were purchased from Sigma Chemical Co.-Aldrich Company (Dorset, UK), unless otherwise stated.

Patient population. Ethical Committee approval for the study was received from the Coombe Women's Hospital. Informed written consent for blood sampling and the study proformas were obtained in all cases and completed by a single investigator (J.G.).

The study population included the following groups:

1. Adult controls: 15 nonpregnant healthy women and 15 men (laboratory and medical colleagues) aged $26-33$ y. Both male and female adults were used in Figure $1 A$. However, because of the disparity between male and female neutrophil apoptosis, we used only female adult control subjects in the remainder of the experiments to standardize results (18).

2. Normal labor (VD): 20 umbilical cord blood samples taken at term after normal pregnancy, labor, and delivery.

3. Elective cesarean (CS): 10 umbilical cord blood samples taken at term after normal pregnancy and elective CS. All
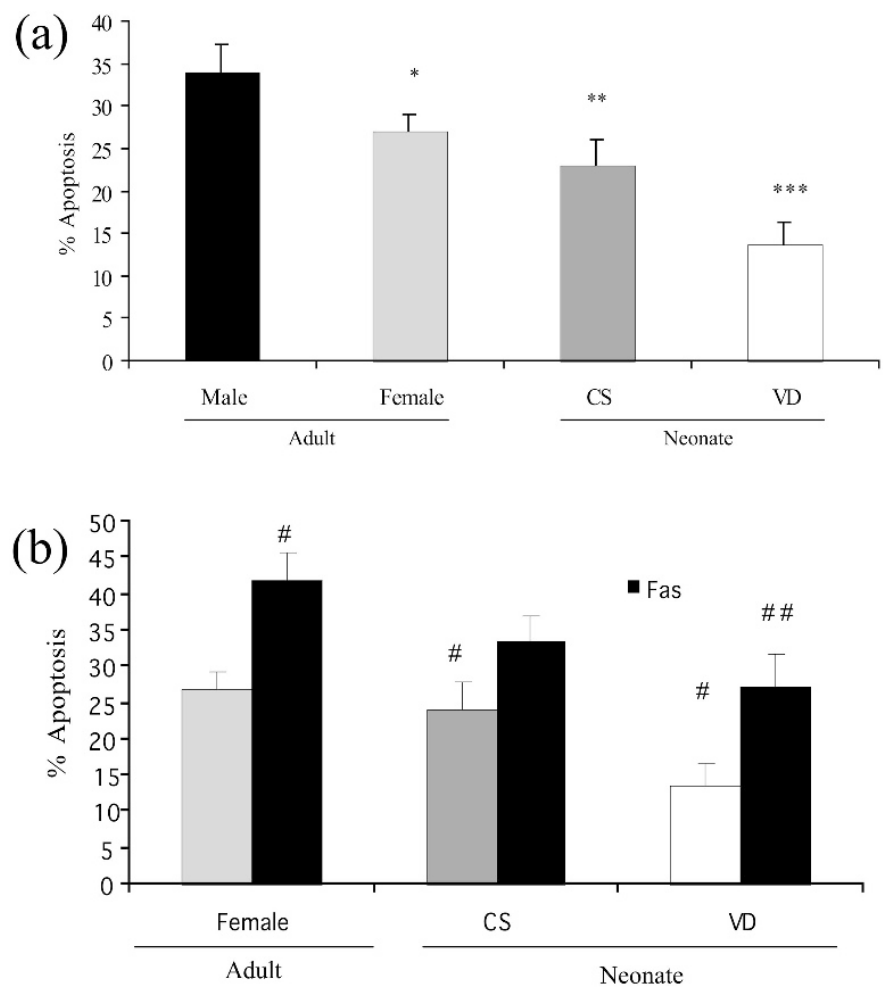

Figure 1. Mode of delivery affects spontaneous $(A)$ and fas-induced $(B)$ neutrophil apoptosis. Neutrophils $\left(1 \times 10^{6} \mathrm{cells} / \mathrm{mL}\right)$ isolated from healthy adult controls (Con; $n=30)$, umbilical cord blood after either VD $(n=20)$ or elective CS $(n=10)$. Neutrophil apoptosis was assessed alone $(A)$ or after incubation with Fas antibody $(100 \mathrm{ng} / \mathrm{mL} ; B)$ at $24 \mathrm{~h}$, by propidium iodide DNA binding staining using flow cytometry. ${ }^{*} p<0.05$ vs male; $* * p<0.05$ $v s$ all other groups; $* * * p<0.05$ vs all other groups; $\# p<0.05 v s$ female spon (spontaneous); \# $<0.05$ vs VD spon (spontaneous). elective CSs were performed under epidural anesthesia using a combination of Bupivacaine, Marcaine, Chirocaine, and Fentanyl.

All infants had a normal uncomplicated postnatal course and were discharged with their mothers.

Preparation of cells. Neutrophils were isolated by dextran (3\%) sedimentation and centrifugation through a discontinuous Ficoll gradient; neutrophil isolation was commenced within 90 min of sampling. Red blood cells were lysed using E-Lyse $(19,20)$. The neutrophil pellet was resuspended in Dulbecco's modified Eagle's medium supplemented with 10\% FCS, 1\% glutamine, $1 \%$ penicillin/streptomycin solution, and Fungizone at a concentration of $1 \times 10^{6}$ cells $/ \mathrm{mL}$. Cells were incubated in polypropylene tubes (Falcon/Becton Dickinson, Cambridge, UK) to prevent adherence. Neutrophil purity as assessed by size, and granularity on flow cytometry was consistently $>95 \%$. Neutrophils at $1 \times 10^{6}$ cells $/ \mathrm{mL}$ were treated with 1 $\mu \mathrm{g} / \mathrm{mL}$ lipopolysaccharide (LPS) where indicated.

Quantification of apoptosis. Spontaneous apoptosis of neutrophils was quantified by flow cytometry as the percentage of cells with hypodiploid DNA $(19,20)$. Cells $\left(1 \times 10^{6}\right.$ cells $\left./ \mathrm{mL}\right)$ were centrifuged at $130 \times g$ for $5 \mathrm{~min}$ and then gently resuspended in $400 \mu \mathrm{L}$ of hypotonic fluorochrome solution (200 mL of PBS, $10 \mathrm{mg}$ of propidium iodide, $3.4 \mathrm{mM}$ sodium citrate, $1 \mathrm{mM}$ Tris, $0.1 \mathrm{mM}$ EDTA, $0.1 \%$ Triton X-100). They were placed on ice for $10 \mathrm{~min}$ before they were analyzed using the Coulter Epics XL-MCL cytofluorometer (Miami, FL, U.S.A.). A minimum of 5,000 events were collected and analyzed. Apoptotic nuclei were distinguished from normal nuclei by their hypodiploid DNA, and debris was excluded from analysis by raising the forward threshold. All measurements were performed under the same instrument settings.

Quantification of cell-surface antigen expression. The expression of CD11b, CD33, and Toll-like receptor-4 (TLR-4) antigens on the surface of neutrophils was measured by flow cytometry. Neutrophils $\left(500 \mu \mathrm{L}\right.$ at $1 \times 10^{6}$ cells $\left./ \mathrm{mL}\right)$ were treated with $10 \mu \mathrm{L}$ of PE-CD11b, PE-CD33, or control antibody and left at $4{ }^{\circ} \mathrm{C}$ for $20 \mathrm{~min}$. The cells were washed three times with $400 \mu \mathrm{L}$ of cold PBS at $130 \times g$ for $10 \mathrm{~min}$ and finally resuspended in $400 \mu \mathrm{L}$ of Isoton II solution and stored on ice before they were analyzed by flow cytometry. Cells (500 $\mu \mathrm{L}$ at $1 \times 10^{6}$ cells $/ \mathrm{mL}$ ) were treated with $1 \mu \mathrm{L}$ of anti-human TLR-4 antibody and incubated at room temperature for $15 \mathrm{~min}$. Wash solution ( $1 \mathrm{~mL}, 2 \%$ FCS in PBS) was added, and the sample was centrifuged at $960 \times g$ for $1 \mathrm{~min}$ at $4^{\circ} \mathrm{C}$. The pellet was resuspended in 1:50 concentration of anti-mouse $\operatorname{IgG}$ conjugated with PE and incubated for $15 \mathrm{~min}$ at room temperature. After an additional $1 \mathrm{~mL}$ wash, the sample was centrifuged at $960 \times g$ for $1 \mathrm{~min}$. The resulting pellet was resuspended in wash, and fluorescence intensity was assessed by flow cytometry and expressed as Ln mean channel fluorescence. The fluorescence intensity is denoted by mean channel fluorescence, which is the average intensity of fluorescence emitted by all cells chosen for measurement and is comparable to the relative number of receptors present on the surface of each cell.

Statistics. Statistical analysis was carried out using ANOVA with Student-Newman correction and $t$ test using Ministat 
(www.ministat.com). Significance was assumed for values of $p$ $<0.05$. Results are expressed as mean \pm SEM unless otherwise indicated.

\section{RESULTS}

Patient demographics. The mean duration of pregnancy in the VD group was $40.1 \pm 1.3 \mathrm{wk}$ and in the CS group was 39.4 $\pm 1.4 \mathrm{wk}(p=0.14)$. Birth weight was $3.4 \pm 0.6 \mathrm{~kg}$ and 3.6 $\pm 0.8 \mathrm{~kg}$ in VD and CS, respectively $(p=0.24)$. The average duration of labor in the VD group was $5.0 \pm 0.1 \mathrm{~h}$. Mean Apgar scores at $1 \mathrm{~min}(\mathrm{VD}, 8.8 \pm 0.6 ; \mathrm{CS}, 8.5 \pm 0.4)$ and 5 min (VD, $9.9 \pm 0.3$; CS, $9.8 \pm 0.4$ ) were also similar in both groups. The indications for elective CS were as follows: six previous $\mathrm{CS}$, one cephalopelvic disproportion, two macrosomia, and one back pain.

Neonates have an altered neutrophil phenotype compared with adults. Neonatal neutrophils have significantly delayed apoptosis compared with adult controls (both male and female). This is further delayed after VD compared with CS ( $p=$ 0.03; Fig. 1A). No direct statistical correlation between labor length and rates of spontaneous apoptosis was found (data not shown).

Adult and neonatal VD neutrophils have a significant increase in apoptosis in response to Fas antibody ( $p=0.001)$. In contrast, Fas antibody does not significantly induce apoptosis in the CS group ( $p=0.13$ ), although levels of apoptosis in Fas-treated cells are equivalent to those in VD neutrophils (Fig. 1B).

CD11b, a marker of neutrophil activation, was decreased on neutrophils from umbilical cord blood at CS compared with adults ( $p=0.04$; Fig. $2 A$ ). There was no difference between adults and VD, which suggests that labor promotes increased CD11b expression. No significant alterations in CD33 expression were found between the groups (Fig. 2B).

Neutrophil priming with LPS is altered by mode of delivery. The ability of labor to prime for an additive response to LPS was also investigated. In adult controls, neutrophil apoptosis is delayed by co-incubation with LPS. Neonatal neutrophils are hyporesponsive to the antiapoptotic effects of LPS before labor ( $p=0.34$; Fig. $3 A$ ) but respond significantly after labor $(p=0.01)$. The percentage of LPS responsiveness was as follows: male, $77.4 \pm 14.8$; female, $68.5 \pm 26.3$; CS, $24.5 \pm$ 7.8; and VD, $42.2 \pm 7.9$. In controls and neonatal neutrophils from infants who were born by VD, there is a significant increase in LPS-induced CD11b expression ( $p=0.01 \mathrm{VD})$ that is not seen in those who were born by CS ( $p=0.15$; Fig. $3 B)$.

LPS signaling in the newborn neutrophil. Both adult controls and neutrophils from infants who were born by VD express similar levels of surface TLR-4. This is significantly up-regulated by LPS co-incubation in both adults $(p=0.008)$ and VD ( $p=0.01$; Fig. 4). CS neutrophils have elevated TLR-4, but this is not up-regulated after stimulation with LPS $(p=0.8)$.

\section{DISCUSSION}

Several studies have demonstrated significant changes in neonatal neutrophil survival and altered responses to various
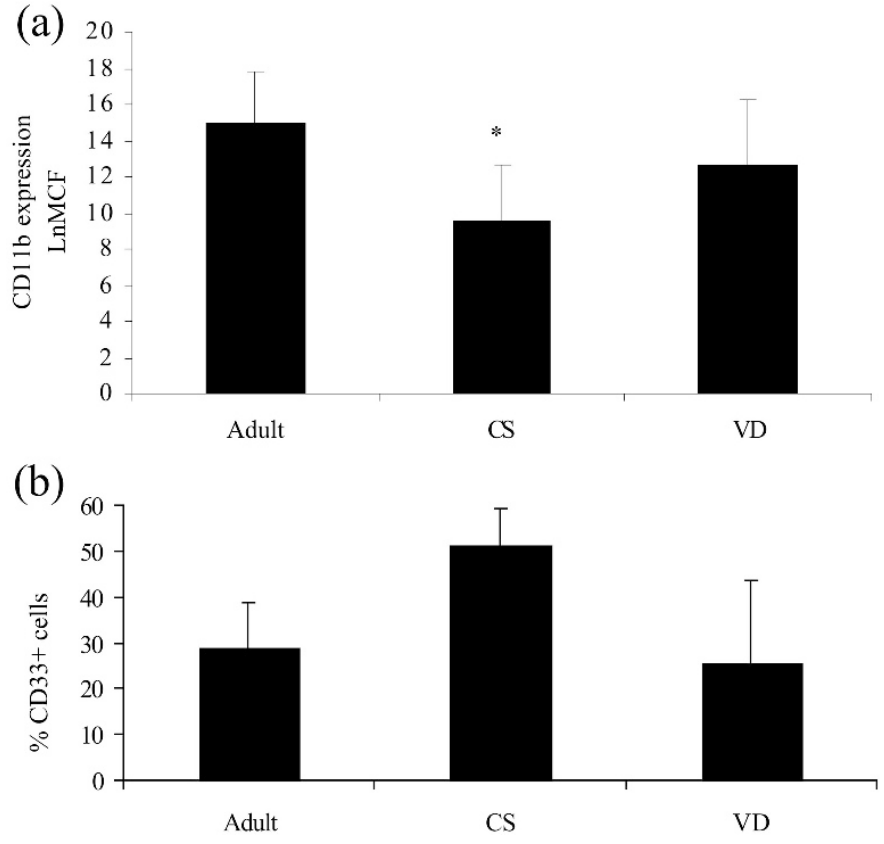

Figure 2. Effects of mode of delivery on inflammatory cell activation $(\mathrm{CD} 11 \mathrm{~b} ; A)$ and neutrophil maturity $(\mathrm{CD} 33 ; B)$. Normal neutrophils $\left(1 \times 10^{6}\right.$ cells $/ \mathrm{mL})$ isolated from healthy adult controls $(n=15)$ and umbilical cord blood after either VD $(n=15)$ or CS $(n=10)$ were assessed for CD11b $(A)$ using a PE-labeled MAb ( ${ }^{*} p<0.05 v s$ Adult). The percentage of CD33 (B) expression was measured in the same groups by incubating $\left(1 \times 10^{6}\right.$ cells $\left./ \mathrm{mL}\right)$ cells with CD33-PE antibody by flow cytometry.

factors (e.g. anti-Fas, G-CSF) in umbilical cord blood after CS with no labor (15,21-23). This is the first article to describe the effect of labor on neutrophil apoptosis. We have shown a significant delay in neutrophil apoptosis in normal term neonates compared with adults. This response was accentuated in infants who were born by VD compared with elective CS and correlates with the increased neonatal neutrophil count after VD $(13,14,24)$. Decreased caspase 3 , an executioner protease that mediates apoptosis, is diminished in umbilical cord neutrophils and may mediate the delayed apoptosis in newborn neutrophils (22)

Labor alters neonatal neutrophil responses. Cortisol is known to delay neutrophil apoptosis (25), and elevated serum cortisol after VD has been shown to correlate with neonatal neutrophil counts $(25,26)$. Similarly, IL-6 is elevated with increasing duration of labor (27) and may be partially responsible for the labor-induced delay in neutrophil apoptosis. CD11b, a surface neutrophil marker of activation, was diminished on neutrophils from VD versus adults and further downregulated in CS. Increased respiratory burst, CD11b/CD18, and IL-8 receptor have been demonstrated after VD in comparison with CS (28).

Neutrophils constitutively express Fas and undergo apoptosis in the presence of Fas ligand (FasL) (29). Neonatal neutrophils are hyporesponsive to Fas-induced apoptosis (15) after CS. In addition, we have found that neutrophils from VD infants are responsive to Fas-induced apoptosis. Uguz et al. (30) found increased Fas expression on neonatal neutrophils after CS versus adults. This suggests that Fas hyporesponsiveness in this group is mediated below the level of the receptor. 
(a)

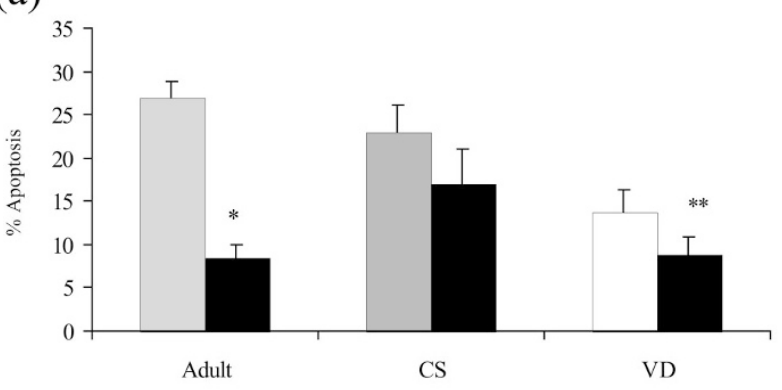

- LPS

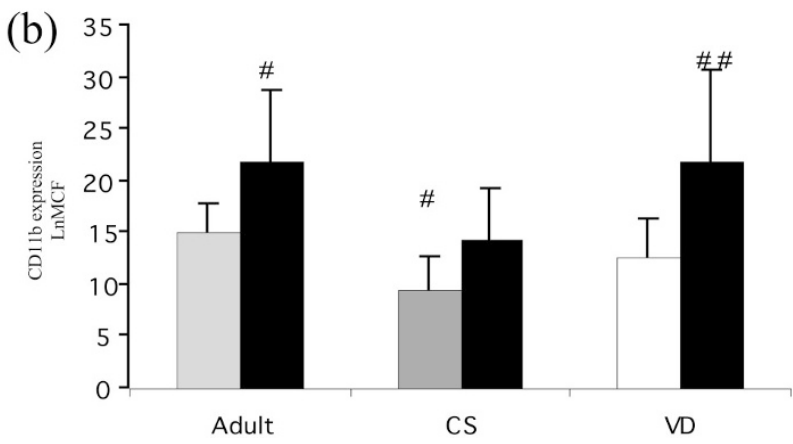

Figure 3. Effects of mode of delivery on neutrophil apoptosis $(A)$ and CD11b expression $(B)$. Normal neutrophils $\left(1 \times 10^{6}\right.$ cells $\left./ \mathrm{mL}\right)$ were incubated for $1 \mathrm{~h}$ before the addition of LPS $(1 \mu \mathrm{g} / \mathrm{mL})$. Cells from healthy adult female control subjects (Adult; $n=15$ ) and umbilical cord blood after either elective CS ( $=10)$ or $\mathrm{VD}(n=15)$ were then assessed for apoptosis by propidium iodide DNA staining after $24 \mathrm{~h}(A)$ or CD11b expression using a FITC-labeled MAb after $6 \mathrm{~h}(B) .{ }^{*} p<0.05 v s$ adult spon; ${ }^{* *} p<0.05 v s$ VD spon; $\# p<0.05 v s$ adult spon; \#\#p $<0.05$ vs VD spon.

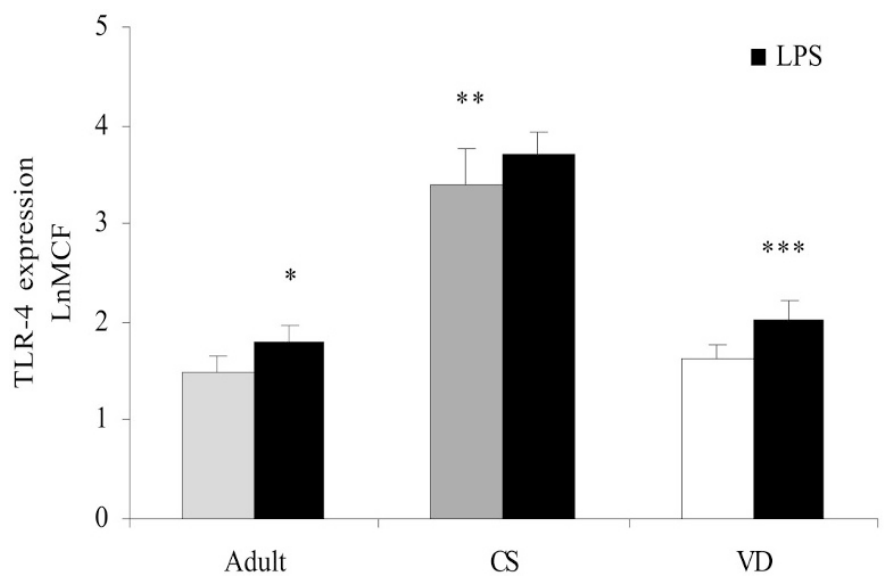

Figure 4. TLR-4 expression is altered by mode of delivery. TLR-4 expression on the surface of neutrophils $\left(1 \times 10^{6}\right.$ cells $\left./ \mathrm{mL}\right)$ was measured by flow cytometry alone or after LPS $(1 \mu \mathrm{g} / \mathrm{mL})$ stimulation. The results are expressed as Ln mean channel fluorescence (LnMCF) in the following groups: healthy adult female controls (Adult; $n=15$ ) and umbilical cord blood after either elective CS $(n=10)$ or $\operatorname{VD}(n=15) ; * p=0.008 v s$ adult; $* * p=0.01 v s \mathrm{VD}$ con (control); $* * * p=0.01$ vs adult con/VD con.

Maintenance of a normal Fas-FasL pathway may be essential to prevent maternal rejection of the fetal allograft. Immunologically active FasL is expressed on trophoblast cells and is down-regulated during labor. Therefore, the process of labor may render the neutrophil relatively more responsive to Fasinduced cell death.
Neutrophil activation has previously been shown to be a function of labor length in preterm infants (31). These authors found no correlation between CD11b and several other surface neutrophil antigens and mode of delivery or gestational age in preterm infants, although labor length did influence these parameters. They did not differentiate between elective CS without labor and emergency CS with labor or the influence of inflammatory conditions such as preeclampsia. Neonates with respiratory distress have increased neutrophil activation (32) and a relative systemic neutropenia. CD11b/CD18 (Mac-1) are similar on neutrophils from adults and neonates through $4 \mathrm{wk}$ of age, but children had decreased up-regulation with LPS (33). Priming of cord blood neutrophils by labor has also been indicated in studies of respiratory burst and alkaline phosphatase activity (34)

After CS, neonatal neutrophils are hyporesponsive to apoptotic and CD11b LPS-induced responses. Toll-like receptors are the transmembrane component of the LPS signaling receptor cluster. They are highly evolutionarily conserved and involved in recognition of "danger signals." Baseline TLR-4 expression on neutrophils from CS is elevated compared with the other groups. The CS group does not up-regulate the TLR-4 expression with LPS, unlike the other two groups. A recent study on trophoblastic TLR-4 expression showed a high baseline expression and no increase with LPS (35). Low-dose LPS can induce "tolerance" in a cell, inducing a state of relative hyporesponsiveness. LPS-tolerant cells can have high levels of TLR-4 expression, but the intracellular LPS signaling mechanism below the level of the receptor is disrupted with decreased activity of the essential enzyme, IRAK kinase (36). This may also be the mechanism underlying the LPS hyporesponsive CS cells with increased basal levels of TLR-4.

The mode of delivery affects the neutrophil phenotype by increasing neutrophil survival and augmenting LPS responsiveness. We suggest that labor of any duration may be immunologically beneficial to the normal term neonate. However, in infants with a preexisting inflammatory condition, such as chorioamnionitis or preeclampsia, triggering further inflammation (i.e. labor) may be detrimental and explain the increased morbidity in this group with labor $(37,38)$. The effect of mode of delivery is an important variable in neonatal neutrophil survival and function and needs to be considered in future research in this area. Further study of the effects of labor on the inflammatory responses of newborns with preexisting inflammation may guide us to the most beneficial mode of delivery for this group.

Acknowledgments. We thank all of the parents and staff who consented to donate blood samples to this project.

\section{REFERENCES}

1. Hales KA, Morgan MA, Thurnau GR 1993 Influence of labor and route of delivery on the frequency of respiratory morbidity in term neonates. Int J Gynaecol Obstet 43:35-40

2. van den Berg A, van Elburg RM, van Geijn HP, Fetter WP 2001 Neonatal respiratory morbidity following elective caesarean section in term infants. A 5-year retrospective study and a review of the literature. Eur J Obstet Gynecol Reprod Biol 98:9-13

3. Hook B, Kiwi R, Amini SB, Fanaroff A, Hack M 1997 Neonatal morbidity after elective repeat cesarean section and trial of labor. Pediatrics 100:348-353

4. Aldridge AJ 2002 Role of the neutrophil in septic shock and the adult respiratory distress syndrome. Eur J Surg 168:204-214 
5. Matute-Bello G, Liles WC, Radella F 2nd, Steinberg KP, Ruzinski JT, Hudson LD, Martin TR 2000 Modulation of neutrophil apoptosis by granulocyte colonystimulating factor and granulocyte/macrophage colony-stimulating factor during the course of acute respiratory distress syndrome. Crit Care Med 28:1-7

6. Ferreira PJ, Bunch TJ, Albertine KH, Carlton DP 2000 Circulating neutrophil concentration and respiratory distress in preterm infants. J Pediatr 136:466-472

7. Brus F, van Oeveren W, Okken A, Oetomo SB 1997 Number and activation of circulating polymorphonuclear leukocytes and platelets are associated with neonatal respiratory distress severity. Pediatrics 99:672-680

8. Grigg JM, Savill JS, Sarraf C, Haslett C, Silverman M 1991 Neutrophil apoptosis and clearance from neonatal lungs. Lancet 338:720-722

9. Matute-Bello G, Liles WC, Radella F 2nd, Steinberg KP, Ruzinski JT, Jonas M, Ch EY, Hudson LD, Martin TR 1997 Neutrophil apoptosis in the acute respiratory distress syndrome. Am J Respir Crit Care Med 156:1969-1977

10. Oei J, Lui K, Wang H, Henry R 2003 Decreased neutrophil apoptosis in tracheal fluids of preterm infants at risk of chronic lung disease. Arch Dis Child Fetal Neonatal Ed 88:F245-F249

11. O'Neill S, O'Neill AJ, Conroy E, Brady HR, Fitzpatrick JM, Watson RW 2000 Altered caspase expression results in delayed neutrophil apoptosis in acute pancreatitis. J Leukoc Biol 68:15-20

12. Brannigan AE, O'Connell PR, Hurley H, O'Neill A, Brady HR, Fitzpatrick JM, Watson RW 2000 Neutrophil apoptosis is delayed in patients with inflammatory bowel disease. Shock 13:361-366

13. Jimenez MF, Watson RW, Parodo J, Evans D, Foster D, Steinberg M, Rotstein OD, Marshall JC 1997 Dysregulated expression of neutrophil apoptosis in the systemic inflammatory response syndrome. Arch Surg 132:1263-1269

14. Delgado I, Neubert R, Dudenhausen JW 1994 Changes in white blood cells during parturition in mothers and newborn. Gynecol Obstet Invest 38:227-235

15. Hasan R, Inoue S, Banarjee A 1993 Higher white blood cell counts and band forms in newborns delivered vaginally compared with those delivered by caesarean section. Am J Clin Pathol 100:116-118

16. Allgaier B, Shi M, Luo D, Koenig JM 1998 Spontaneous and Fas-mediated apoptosis are diminished in umbilical cord blood neutrophils compared with adult neutrophils. J Leukoc Biol 64:331-336

17. Barak Y, Blachar Y, Levin S 1980 Neonatal neutrophilia: possible role of a humoral granulopoietic factor. Pediatr Res 14:1026-1028

18. Molloy EJ, O'Neill AJ, Grantham JJ, Sheridan-Pereira M, Fitzpatrick JM, Webb DW Watson RW 2003 Sex-specific alterations in neutrophil apoptosis: the role of estradio and progesterone. Blood 102:2653-2659

19. Watson RW, O’Neill A, Brannigen AE, Coffey R, Marshall JC, Brady HR, Fitzpatrick JM 1999 Regulation of Fas antibody induced neutrophil apoptosis is both caspase and mitochondrial dependent. FEBS Lett 453:67-71

20. Nicoletti I, Migliorati G, Pagliacci MC, Grignani F, Riccardi C 1991 A rapid and simple method for measuring thymocyte apoptosis by propidium iodide staining and flow cytometry. J Immunol Methods 139:271-279

21. Yang KD, Chen M-Z, Teng R-J, Yang M-Y, Liu H-C, Chen R-F, Hsu T-Y, Shaio M-F 2000 A model to study antioxidant regulation of endotoxemia-modulated neonatal granulopoiesis and granulocyte apoptosis. Pediatr Res 48:829-834

22. Uguz A, Coskun M, Yuzbey S, Kizilors A, Karadogan I, Gura A, Yoldas B, Oygur N, Yegin O 2002 Apoptosis of cord blood neutrophils and their response to colonystimulating factors. Am J Perinatol 19:427-434
23. Luo D, Schowengerdt KO Jr, Stegner JJ, May WS Jr, Koenig JM 2003 Decreased functional caspase-3 expression in umbilical cord blood neutrophils is linked to delayed apoptosis. Pediatr Res 53:859-864

24. Chirico G, Gasparoni A, Ciardelli L, Martinotti L, Rondini G 1999 Leukocyte counts in relation to the method of delivery during the first five days of life. Biol Neonate 75:294-299

25. Meagher LC, Cousin JM, Seckl JR, Haslett C 1996 Opposing effects of glucocorticoids on the rate of apoptosis in neutrophilic and eosinophilic granulocytes. J Immunol 156:4422-4428

26. Sybulski S, Maughan GB 1976 Cortisol levels in umbilical cord plasma in relation to labor and delivery. Am J Obstet Gynecol 125:236-238

27. Chiesa C, Signore F, Assumma M, Buffone E, Tramontozzi P, Osborn JF, Pacifio L 2001 Serial measurements of C-reactive protein and interleukin-6 in the immediate postnatal period: reference intervals and analysis of maternal and perinatal confounders. Clin Chem 47:1016-1022

28. Gessler P, Dahinden C 2003 Increased respiratory burst and increased expression of complement receptor-3 (CD11b/CD18) and of IL-8 receptor-A in neutrophil granulocytes from newborns after vaginal delivery. Biol Neonate 83:107-112

29. Liles WC, Kiener PA, Ledbetter JA, Aruffo A, Klebanoff SJ 1996 Differential expression of Fas (CD95) and Fas ligand on normal human phagocytes: implications for the regulation of apoptosis in neutrophils. J Exp Med 184:429-440

30. Balkundi DR, Hanna N, Hileb M, Dougherty J, Sharma S 2000 Labor-associated changes in Fas ligand expression and function in human placenta. Pediatr Res 47:301-308

31. Weinschenk NP, Farina A, Bianchi DW 1998 Neonatal neutrophil activation is a function of labor length in preterm infants. Pediatr Res 44:942-945

32. Nupponen I, Pesonen E, Andersson S, Makela A, Turunen R, Kautiainen H, Repo H 2002 Neutrophil activation in preterm infants who have respiratory distress syndrome. Pediatrics 110:36-41

33. Kim SK, Keeney SE, Alpard SK, Schmalstieg FC 2003 Comparison of L-selectin and $\mathrm{CD} 11 \mathrm{~b}$ on neutrophils of adults and neonates during the first month of life. Pediatr Res 53:132-136

34. Khalfan L, Karlsson A, Lundqvist H, Bjorksten B, Dahlgren C 1995 Lack of correlation between NADPH-oxidase priming and elevated alkaline phosphatase activity in cord blood neutrophils. Pediatr Allergy Immunol 6:161-164

35. Holmlund U, Cebers G, Dahlfors AR, Sandstedt B, Bremme K, Ekstrom ES, Scheynius A 2002 Expression and regulation of the pattern recognition receptors Toll-like receptor-2 and Toll-like receptor-4 in the human placenta. Immunology 107:145-151

36. Medvedev AE, Lentschat A, Wahl LM, Golenbock DT, Vogel SN 2002 Dysregulation of LPS-induced toll-like receptor 4-MyD88 complex formation and IL-1 receptor-associated kinase 1 activation in endotoxin-tolerant cells. J Immunol 169:52095216

37. Baud O, Ville Y, Zupan V, Boithias C, Lacaze-Masmonteil T, Gabilan JC, Frydman R, Dehan M 1998 Are neonatal brain lesions due to intrauterine infection related to mode of delivery? Br J Obstet Gynaecol 105:121-124

38. Verma U, Tejani N, Klein S, Reale MR, Beneck D, Figueroa R, Visintainer P 1997 Obstetric antecedents of intraventricular haemorrhage and periventricular leukomalacia in the low-birth-weight neonate. Am J Obstet Gynecol 176:275-281 